\title{
But How Homeless Are You? Toward a More Just and Effective Response to Youth Homelessness
}

\section{Casey Holtschneider ${ }^{1}$}

Accepted: 24 March 2021 / Published online: 27 June 2021

(C) Association for Behavior Analysis International 2021

\begin{abstract}
Each year, an estimated 4,200,000 unaccompanied youth ages 13 to 25 experience homelessness in the United States. The threats facing young people in housing crisis are many, and their potential impacts, harrowing. Youth are at high risk for physical and sexual victimization, mental and physical illness, and involvement with the criminal legal system and face serious threats to their education, their future economic stability, and their lives. Despite these dangerous consequences, the response to this issue in the United States continues to lack urgency, meaningful investment, and empirical support. This article critically examines the current approach to services for youth in situations of homelessness in the United States. Directly informed by the lived experiences of young people, it calls for a shift in understanding of the nature and scope of the problem and, consequently, the practice and policy strategies being implemented to address it. Specifically, the U.S. Department of Housing and Urban Development's definition of homelessness, along with corresponding procedures that further limit access to services, is examined in a call to change course in response to youth homelessness.
\end{abstract}

Keywords Youth homelessness $\cdot$ Housing policy $\cdot$ Homeless services $\cdot$ Housing instability

Tierra $^{1}$ emailed the youth organization I work with looking for support. She was 23 years old and 8 months pregnant and had been homeless for the past year. Her coworker, after learning that she was sleeping on the train, had been letting Tierra stay with her and her boyfriend for the last 3 months in their studio apartment. Tierra told us she knew she had long overstayed her welcome, but her baby was due soon, and she had no other support and no place to go.

Juan, 18, called us from a friend's phone. He had heard from that friend that we had gift cards for the local grocery store and was wondering if we might be able to help him

${ }^{1}$ All youth names have been changed for confidentiality.

Casey Holtschneider

c-holtschneider@neiu.edu

1 Social Work Program, Northeastern Illinois University, Chicago, IL, USA 
with one. Juan had lost his restaurant job due to the COVID-19 pandemic and had been unable to find work since. He wanted the gift card to give to his aunt so she would not make him leave her apartment, where, before he was laid off, he had been paying her rent to stay. The small apartment was overcrowded with other relatives, and his aunt had made it clear he must contribute financially or go.

We met Sara, 25, when a staff member at another youth organization contacted us to see if we could help. Sara had recently lived in their housing program where she was thriving-working a part-time job she enjoyed, enrolled full time in college, and starting to build trusting relationships with people after years of experiences of violence. This came to an end on her 25th birthday, as the program could only support youth through the age of 24. Sara, with nowhere to go, lost her job, dropped out of school, and was surviving by meeting random people online, going to their homes at night, and staying in dangerous situations for days and weeks at a time in order to avoid having to enter the adult emergency shelter system.

Tierra, Juan, and Sara are three of an estimated 4,200,000 unaccompanied youth ages 13-25 who experience homelessness in the United States each year (Morton et al., 2017). Although they each have their own unique story, an experience these three young people have in common is that they are each facing homelessness and none of them qualify for housing through the City of Chicago's homeless response system. This article examines the dissonance between the rhetoric of homeless service systems and providers and their actual practices on the ground. It explores the dangers of the current status-quo response rooted in neoliberalism and argues that in order to make any progress in addressing youth homelessness, there must be a shift in the target for change.

\section{Who Deserves Help?}

In our foundation social welfare policy course, my social work graduate students learn about England's Elizabethan Poor Law of 1601. Sadly, we teach this not because of the old adage that those who do not know history are doomed to repeat it, but rather because over 400 years later in the United States, the principles on which it was created persist in contemporary policy solutions to social problems. Hallmarks of the Poor Law of 1601 (a consolidation of several previous poor laws enacted throughout the 16th century) include an explicit distinction between the deserving and the undeserving poor, the rhetoric of personal responsibility, warnings that public assistance encourages laziness, and a complete disregard for the systemic roots of poverty and suffering (Yerli, 2020). It arguably had no moral interest in equity or alleviating distress, but rather sought social control as it came in a time where many poor people were facing severe hunger and desperation and leaders feared their uprising (McIntosh, 2011). The colonizers of this country carried these principles with them into their earliest approaches to poverty intervention, and today one does not have to look further than the morning headlines to see their staying power.

These same principles continue to be embedded in the US capitalist economic system and its dangerous outgrowth of neoliberalism. The belief that the private market will work all things out through competition has had a devastating effect on social services (Dello Buono, 2018). When an entire system is predicated on the goal of 
maximizing wealth at the expense of the social conditions of people, the consequences run deep. The government's role becomes that of a facilitator of markets rather than a caretaker of people. Basic human rights and well-being are viewed as private commodities rather than a public good. People are seen as consumers of services rather than citizens entitled to care and support. Social service organizations are forced to shift their focus to the bottom line rather than quality services (just see the rise in funding application criteria focused on efficiencies, scalability, and other marketized concepts coded with terms such as "impact investment"). And of particular relevance for this article, the safety net for vulnerable people grows increasingly smaller and becomes more tightly controlled (Baines, 2017).

\section{How Homeless Are You?}

So what does the Elizabethan Poor Law and neoliberalism have specifically to do with how we approach services for youth facing homelessness? Everything. The experience of homelessness for young people is monumentally dangerous. Youth are at high risk for physical and sexual victimization, mental and physical illness, and involvement with the criminal legal system and face serious threats to their education, their future economic stability, and their lives (Coates \& McKenzie-Mohr, 2010; Edidin et al., 2012; Toro et al., 2007; Whitbeck, 2009). There is no question as to the extent of the harms faced; they have been, and continue to be, widely researched. Yet still, our pervading national response continues to be sparing, time limited, for the proven "deserving" only, and operated through underfunded private agencies staffed by underpaid, marginalized employees, with interventions centered on individual behavior change and surveillance, and the success of those interventions (and therefore continued funding) determined by near-term individual gains and outcomes connected to concepts of self-sufficiency - all of this by the hands of organizations and social service professionals who claim to believe that housing is a human right (Beckhardt et al., 2020; Tars, 2016)

A particularly illuminating example of this dissonance between espousing the belief that housing is a human right and actively promoting the adoption of neoliberalism in practice can be found in a process that is known within the homeless service system as coordinated entry (for one example, see Chicago Continuum of Care, 2020). The U.S. Department of Housing and Urban Development (HUD) requires that regional bodies receiving HUD funding known as continuums of care (CoCs) implement a centralized entry process for people to access housing support. HUD explains coordinated entry as "a process developed to ensure that all people experiencing a housing crisis have fair and equal access and are quickly identified, assessed for, referred, and connected to housing and assistance based on their strengths and needs" (HUD, n.d., p. 1). At first read, this seems to make good sense - have one central place and process for people to get help; however, the system has never been designed to support, as HUD claims, "all people experiencing a housing crisis." First, the manner in which HUD has restricted the definition of homelessness and, second, the complicity of CoCs in the further limiting of services through unsupported ranking systems of risk provide a clear example of neoliberalism at work by the hands of those claiming to be on the side of just policy solutions. 


\section{Definitions}

According to HUD, there are four categories of homelessness that may apply to young people (Table 1; HUD, 2014, p.1). Falling into one of these categories is essential, as without doing so, one is not eligible to enter a CoC's coordinated entry system and therefore is unable to connect to housing resources. Category 3, "homeless under other statutes," was added in response to years of sustained advocacy for HUD to adopt the data-driven definition used by the U.S. Department of Education, which defines homelessness for youth as "lacking a fixed, adequate nighttime residence," explicitly including young people in situations where they are doubled up (sharing the housing of other persons due to economic hardship or a loss of housing) or couch surfing (moving frequently from one temporary living situation to another). HUD eventually agreed to a rule change to partially incorporate this guidance from advocates; however, HUD did so by adding four further conditions required to meet the category (National Alliance to End Homelessness, 2012), thereby continuing to exclude potentially hundreds of thousands of young people in need of support.

The observations presented here are far from novel. The restrictive nature of HUD's definition is felt and discussed every day around this country by those experiencing harm from its exclusions, and the need for reform has been cited by many (Kao et al., 2015; National Network for Youth, 2015; Wiltz, 2019). This is because the data are clear that the predominant experience of homelessness for young people in the United States is that of couch surfing /or being doubled up. In a national study, independent policy research center Chapin Hall found that $72 \%$ of young people currently in shelters or on the street reported experiences of couch surfing or being doubled up (Morton et al., 2017). In my own city, the Chicago Coalition for the Homeless estimates that of the over 16,000 unaccompanied youth who were homeless in Chicago in 2018, 94\% had experiences of being doubled up (Carlson \& Mendieta., 2020). So why, if everyone doing the work on the ground knows it, and the empirical data support it, does HUD not change their definition? Well, we do not have to dig too deep for an

Table 1 U.S. Department of Housing and Urban Development Categories of Homelessness

\begin{tabular}{|c|c|}
\hline Category & Definition \\
\hline $\begin{array}{l}\text { Category 1: literal } \\
\text { homelessness }\end{array}$ & $\begin{array}{l}\text { Individuals or families who live in a place not meant for human habitation } \\
\text { (including the streets or in their car), emergency shelter, transitional } \\
\text { housing, or hotel paid for by a government or charitable organization }\end{array}$ \\
\hline $\begin{array}{l}\text { Category 2: imminent risk of } \\
\text { homelessness }\end{array}$ & $\begin{array}{l}\text { Individuals or families who will lose their primary nighttime residence within } \\
14 \text { days and have no other resources or support networks to obtain other } \\
\text { permanent housing }\end{array}$ \\
\hline $\begin{array}{l}\text { Category } 3 \text { : homeless under } \\
\text { other statutes }\end{array}$ & $\begin{array}{l}\text { Unaccompanied youth under } 25 \text { years of age or families with children and } \\
\text { youth who do not meet any of the other categories but are homeless under } \\
\text { other federal statutes, have not had a lease and have moved } 2 \text { or more } \\
\text { times in the past } 60 \text { days, and are likely to remain unstable because of } \\
\text { special needs or barriers }\end{array}$ \\
\hline $\begin{array}{l}\text { Category } 4 \text { : fleeing domestic } \\
\text { violence }\end{array}$ & $\begin{array}{l}\text { Individuals or families who are fleeing or attempting to flee domestic } \\
\text { violence, dating violence, sexual assault, or stalking and who lack } \\
\text { resources and support networks to obtain other permanent housing }\end{array}$ \\
\hline
\end{tabular}


answer, as HUD has directly provided one through their vigorous opposition for the past few years to the Homeless Children and Youth Act, which seeks to expand the definition (Homeless Children and Youth Act, 2019). HUD's explanation, articulated plainly by the National Alliance to End Homelessness in a statement against the bill, is that expanding the definition would mean more people would need to be helped, and there are not enough resources to do so (National Alliance to End Homelessness, 2015). Putting forth an argument of scarcity when in 2019 the United States led the world in growth of financial assets (as well as in wealth inequality) is a perfect example of how our efforts to address youth homelessness continue to reflect policy from 400 years ago, remaining without any moral interest in truly moving toward equity or the alleviation of distress (Ewing, 2020). The fact that the argument "we can't count more people being harmed because we don't have the resources to help them" is an accepted response to human suffering (notably cosigned and elevated by what is supposed to be a leading advocacy body for those experiencing homelessness in the United States) suggests that the same principles that brought England the Poor Law and that fuel the rise of neoliberalism in social services are alive and well.

\section{Prioritization}

In one of our weekly team meetings, my colleague, a youth peer advocate, was reporting back on her experience of accompanying a young person to complete a coordinated entry assessment a few days earlier. It was an intense and emotional experience for both of them, as the worker completing the assessment coldly asked a deluge of personal — and at times, painful—questions. My colleague said, "It was like they were saying to her, we understand you are homeless, but how homeless are you?" This young advocate was still shaken as she relayed to our team how awful and demoralizing it felt.

For the few who do meet the restrictive HUD definition of homelessness and are able to access the coordinated entry system for services, the barriers to receiving support are not over. HUD calls for CoCs, even after screening out all who do not fit into the categories in Table 1, to "prioritize assistance based on vulnerability and severity of service needs to ensure that people who need assistance the most can receive it in a timely manner" (Corporation for Supportive Housing, 2018, p. 4). This means that each $\mathrm{CoC}$ controls its own system of determining just who needs help the most (HUD, 2015). A number of CoCs across the country use "vulnerability" assessment tools that have been shown to not be reliable or valid (e.g., see Brown et al., 2018, for a look at the Vulnerability Index-Service Prioritization Decision Assistance Tool, which is used in over 1,000 communities to determine access to services) or they make other arbitrary, non-research-based decisions about who is more at risk (e.g., see Carvlin, 2020, for Chicago's youth vulnerability index, and All Chicago, 2019, for Chicago's full prioritization plan). These tools and criteria are at best not useful, as situations for those facing homelessness change often and rapidly, and they are at worst deadly, as they assume that some forms of homelessness are not as perilous as others. All situations of homelessness are highly dangerous, and if those leading our systems genuinely believe housing is a human right, then all experiences are equally critical for us to end as soon as possible. We must move to a response where no person experiencing homelessness is "less homeless" than someone else. 


\section{Whose Behavior Needs to Change?}

In my work, I am often asked by prospective funders, "What is your theory of change?" What I am really being asked here, and notably, often by individuals who have been the direct beneficiaries of our country's embrace of unbridled wealth, is "How are you going to fix the individual deficiencies of young people to end their homelessness?" and the follow-up "How 'efficiently' can you do it?" As the field of behavior analysis turns its attention in a deliberate and focused effort to contribute its specialized knowledge base to address entrenched social issues, so must it turn its target for change from the symptoms to the root causes and to those with the power to demand, and enact, system-wide change.

The current homeless response system sees the problem behavior of a young person unable to meet their economic needs as located within that individual. This dangerous belief pervades the system, callously ignoring overwhelming evidence of the direct causality between poverty and oppression at every turn. A few years ago, I conducted a study to better understand what was happening for young people who had experienced homelessness after they left services with the goal of trying to identify what interventions were most helpful and why (Holtschneider, 2016b). There were two key findings of this research. First, the answer to youth homelessness is not complex: Housing, people, and a resource-rich environment are the intervention. Young people must be invested in, deeply and holistically, by people who genuinely care about them. Second, the intervention (housing, people, and a resource-rich environment) cannot be withdrawn. In 2020, 52\% of 18- to 29-year-olds were living with a parent (Fry et al., 2020), and well before the economic crisis of the COVID-19 pandemic, $70 \%$ of 18 - to 34 year-olds received financial assistance from a parent, a third of which received regular help with their rent/mortgage payments (Merrill Lynch \& Age Wave, 2019). The rhetoric of personal responsibility and self-sufficiency that pervades policy making (and funding) in the area of poverty and homelessness is not reflective of the experiences of the vast majority of young adults in the United States who continue to receive economic support from their parents (Holtschneider, 2016a). When one considers that Black and Latinx youth are at increased risk of experiencing homelessness (83\% and $33 \%$ greater risk respectively; Morton et al., 2017), the racism embedded in this rhetoric becomes clear. It just simply is not the case that a limited amount of services can set up any young adult to go it alone, never mind counteracting the systemic racism youth of color face that continues to define this country.

Make no mistake: Work to provide direct services to victims of oppressive systems is essential to reduce harm and save lives; however, it will never end homelessness. Mullaly's (2007) critical scholarship in the field of social work is explicit: Poverty cannot be eliminated in a capitalist society as it is not an unfortunate by-product but rather an inherent, critical feature of an economic structure that is dependent on exploitation. There are powerful actors who have an active interest in maintaining poverty, and the solution lies in their defeat. Although I am a social worker and not a behavior analyst, I know enough to understand that behavior is selected by consequences, and therefore, it seems work to end homelessness would be best targeted at ceasing rewards for prioritizing profit over people by ending the systems that do so. The targets for change must be those whose behaviors maintain an economic system that causes a young person to experience homelessness in the first place. The targets for 
change must be those who are complicit in a homeless service system that hides behind false narratives of scarcity and rations resources through bureaucratic requirements and non-research-based characterizations of risk. The targets for change must be the behaviors of the people preserving systems that continue to blame and punish young people for the structural violence they endure as a result of oppression.

\section{What We Can Do Right Now}

Six years ago, after being unable to tolerate any longer the failures within the homeless service system (coordinated entry, the focus of this article, being only one of many) and fueled by the findings of my research with young people about the changes required, I and a group of former youth participants and workers within homeless service programs joined together to launch our Chicago-based organization. No longer willing to tell a single young person, "Sorry, we can't help you," we built a place where support is truly unconditional. The first part of our mission is quite simple: to support every young adult who contacts us, with whatever they need, for as long as they want us by their side. Although our work is targeted to Chicago young people ages 18 to 30 impacted by poverty and homelessness, we have no age limits, no time limits, no prepackaged services, no intakes or discharges, no unnecessary assessments, no geographic limits, no documentation requirements, and no definitions of current levels of crisis a young person must be experiencing for us to help. We serve every youth as they come to us on a first-come-first-serve basis, ensuring we are never making assumptions about a person's level of risk. We are a small team, all of us simultaneously providing direct services and handling the administrative functions of the organization, and in six years we have never turned a single person away. We invest in any and all parts of young people where they would like support. This includes housing, of course, but also education, employment, physical and emotional health, legal support, and more. We provide direct cash assistance and respect young people enough to not surveil their use of that assistance. We play basketball. We make music and art. We provide space and time for youth to rest. We go to baby showers and court hearings. We deliver diapers and food. We fight alongside youth in their dean's office and with their landlords. In short, we help however we can for as long as a young person wants us to.

Direct support is a critical part of our work. The majority of the young people we serve either do not meet the HUD definition of homelessness required to access the coordinated entry system for help or they do and are waiting, some literally for years now, to get a call back, as they have not been "prioritized" as needing support. These services, although a significant part of what we do, are only the first part of our mission as an organization. The second is to end harmful systems that cause young people to need our help in the first place. And the third is to build a more just and equitable world together with all who aspire to do better by young people. It is our hope that you will join us in this work. 
Author's contributions Not applicable.

\section{Declarations}

Conflicts of interest The corresponding author states that there is no conflict of interest.

Ethics approval Not applicable.

Consent to participate Not applicable.

Consent for publication Not applicable.

\section{References}

All Chicago. (2019). Chicago coordinated entry 2019 prioritization plan. https://d155kunxflaozz.cloudfront. net/wp-content/uploads/2020/11/Chicago-CE-Prioritization-Chart-2019.pdf

Baines, D. (Ed). (2017). Doing Anti-Oppressive Practice: Social Justice Social Work (3rd ed). Blackpoint, NS: Fernwood Publishing.

Beckhardt, M., Boden, P., \& LS, J. (2020, April 24). Housing is a human right. It should not be predicated on the money in one's pocket. The Appeal https://theappeal.org/housing-is-a-human-right/.

Brown, M., Cummings, C., Lyons, J., Carrión, A., \& Watson, D. P. (2018). Reliability and validity of the Vulnerability Index-Service Prioritization Decision Assistance Tool (VI-SPDAT) in real-world implementation. Journal of Social Distress and Homelessness, 27(2), 110-117. https://doi.org/10.1080/ 10530789.2018.1482991.

Carlson, S., \& Mendieta, D. (2020). Estimate of homeless people in Chicago (2018). Chicago Coalition for the Homeless https://www.chicagohomeless.org/estimate.

Carvlin, A. (2020). Chicago coordinated entry system - Youth vulnerability index. All Chicago https://hmis. allchicago.org/hc/en-us/articles/115001704526-Youth-Vulnerability-Index-VI.

Chicago Continuum of Care. (2020). Chicago continuum of care's community standards. All Chicago https:// allchicago.org/wp-content/uploads/2020/09/IL-510-Community-Standards-Approved-2020.02.pdf.

Coates, J., \& McKenzie-Mohr, S. (2010). Out of the frying pan, into the fire: Trauma in the lives of homeless youth prior to and during homelessness. Journal of Sociology and Social Welfare, 37(4), 65-96.

Corporation for Supportive Housing. (2018). Coordinated entry system continuum of care IL 510: Policies and procedures guide. https://www.csh.org/wp-content/uploads/2018/02/CES-Policy-and-ProcedureGuide_January.pdf

Dello Buono, R. A. (2018). Crisis neoliberalism and the social welfare state: Structural challenges and policy responses. In M. A. Fallov \& C. Blad (Eds.), Social welfare responses in a neoliberal era (pp. 18-43). Brill. https://doi.org/10.1163/9789004384118_003.

Edidin, J. P., Ganim, Z., Hunter, S. J., \& Karnik, N. S. (2012). The mental and physical health of homeless youth: A literature review. Child Psychiatry and Human Development, 43(3), 354-375. https://doi.org/10. 1007/s10578-011-0270-1.

Ewing, J. (2020, September 23). United States is the richest country in the world and it has the biggest wealth gap. The New York Times.https://www.nytimes.com/2020/09/23/business/united-states-is-the-richestcountry-in-the-world-and-it-has-the-biggest-wealth-gap.html.

Fry, R., Passel, J. S., \& Cohn, D. (2020, September 4). The majority of young adults in the U.S. live with their parents for the first time since the Great Depression. Pew Research Center. https://www.pewresearch.org/ fact-tank/2020/09/04/a-majority-of-young-adults-in-the-u-s-live-with-their-parents-for-the-first-timesince-the-great-depression/

Holtschneider, C. (2016a). From independence to interdependence: Redefining outcomes for transitional living programs for youth experiencing homelessness. Families in Society, 97, 160-170. https://doi.org/ 10.1606/1044-3894.2016.97.26

Holtschneider, C. (2016b). A part of something: The importance of transitional living programs within a Housing First framework for youth experiencing homelessness. Children and Youth Services Review, 65, 204-215. https://doi.org/10.1016/j.childyouth.2016.04.009 
Homeless Children and Youth Act of 2019, H.R. 2001, 116th Cong. (2019). https://www.congress.gov/bill/ 116th-congress/house-bill/2001

Kao, J. S., Kim, E. T., \& Nasser, H. E. (2015, January 31). Who counts as homeless depends on how you ask. Al Jazeera America. http://america.aljazeera.com/multimedia/2015/1/who-countsas-homeless-dependson-how-you-ask.html

McIntosh, M. (2011). The Poor Laws of 1598 and 1601. In Poor relief in England, 1350-1600 (pp. 273-293). Cambridge University Press. https://doi.org/10.1017/CBO9781139057547.014

Merrill Lynch \& Age Wave. (2019). Early adulthood: The pursuit of financial independence. AgeWave https://agewave.com/what-we-do/landmark-research-and-consulting/research-studies/early-adulthood/.

Morton, M. H., Dworsky, A., \& Samuels, G. M. (2017). Missed opportunities: Youth homelessness in America. National estimates. Chapin Hall at the University of Chicago. https://voicesofyouthcount.org/ wp-content/uploads/2017/11/ChapinHall_VoYC_NationalReport_Final.pdf.

Mullaly, R. P. (2007). The new structural social work: Ideology, theory, practice (3rd ed.). Oxford University Press.

National Alliance to End Homelessness. (2012, January 18). Changes in HUD definition of homeless. http:// endhomelessness.org/wp-content/uploads/2012/01/changes-in-hud-definition-homeless.pdf

National Alliance to End Homelessness. (2015, May 15). Opposition statement to the Homeless Children and Youth Act. https:/endhomelessness.org/resource/opposition-statement-to-homeless-children-and-youthact/

National Network for Youth. (2015, July 2). Over 400 organizations support the Homeless Children and Youth Act. https://nn4youth.org/2015/06/03/over-350-organizations-support-the-homeless-children-andyouth-act-nn4y-is-one-of-them/

Tars, E. (2016). Housing as a human right. National Low Income Housing Coalition https://nlihc.org/sites/ default/files/2016AG_Chapter_1-6.pdf.

Toro, P. A., Dworsky, A., \& Fowler, P. J. (2007). Homeless youth in the United States: Recent research findings and intervention approaches. The 2007 National Symposium on Homelessness Research. Washington, DC: U.S. Department of Housing and Urban Development and U.S. Department of Health and Human Services. https://aspe.hhs.gov/report/toward-understandinghomelessness-2007-national-symposium-homelessness-research-homeless-youth-united-states-recentresearch-findings-and-intervention-approaches.

U.S. Department of Housing and Urban Development. (2014, October). HUD's homeless definition as it relates to children and youth. https://files.hudexchange.info/resources/documents/HUDs-HomelessDefinition-as-it-Relates-to-Children-and-Youth.pdf

U.S. Department of Housing and Urban Development. (2015, February). Coordinated entry policy brief. https://files.hudexchange.info/resources/documents/Coordinated-Entry-Policy-Brief.pdf

U.S. Department of Housing and Urban Development. (n.d.). Coordinated entry and homeless management information systems. https://files.hudexchange.info/resources/documents/Coordinated-Entry-and-HMISFAQs.pdf

Whitbeck, L. B. (2009). Mental health and emerging adulthood among homeless young people. Psychology Press.

Wiltz, T. (2019, November 22). Redefining homelessness could help families on the edge, advocates say. Pew Charitable Trusts https://www.pewtrusts.org/en/research-and-analysis/blogs/stateline/2019/11/22/ redefining-homelessness-could-help-families-on-the-edge-advocates-say.

Yerli, K. (2020). The Elizabethan Poor Law of 1601 as a result of socio-political and economic conditions of the sixteenth century England. Turkish Journal of Applied Social Work, 3(1), 88-99. 